\title{
What is New in New Generation Calcium Channel Blocker
}

\author{
*MMR Siddiqui ${ }^{1}$, SS Binte Mosharraf ${ }^{2}$, RS Giasuddin ${ }^{3}$, N Islam $^{4}$, S Mirza $^{5}$
}

\begin{abstract}
Hypertension is a multifactorial and multisystem disease in which elevated blood pressure is only one sign of multiple underlying physiological abnormalities. It affects approximately $26 \%$ of the population worldwide. Hypertension is one of the leading cause of death as a "silent killer". Several classes of antihypertensive agents have been in clinical use, but CCBs exert most potent antihypertensive action and are widely used as a first line antihypertensive drug in elderly with very few contraindication.Four generations of dihydropyridines CCBs are now available.The fourth-generation highly lipophilic dihydropyridines, lercanidipine, cilnidipine and lacidipine are now available which provide a real degree of therapeutic comfort in terms of stable activity, a reduction in adverse effects and a broad therapeutic spectrum. Cilnidipine is a recently developed CCB, and possesses both L- and N-type calcium channel blocking activity.Cilnidipine causing less reflex tachycardia, less pedal edema, better control of proteinuria, suppressing podocyte damage, increasing insulin sensitivity. This article reviews the current understanding of the pharmacological profile and clinical utility of cilnidipine as a unique antihypertensive drug.
\end{abstract}

Key Words: Hypertension, Calcium Channel Blocker, Cilnidipine, N-type calcium channel.

\section{Introduction}

Hypertension is a universal public health problem and one of the most important risk factors for cardiovascular diseases, including ischemic heart diseases, heart failure, cerebrovascular disease, dementia, vision loss, and kidney failure. ${ }^{1}$ Hypertension is a multifactorial and multisystem disease in which elevated blood pressure is only one sign of multiple underlying physiological abnormalities. It affects approximately $26 \%$ of the population worldwide, nearly $45 \%$ of deaths by heart disease and $51 \%$ of deaths by stroke are due to hypertension; accounting for 9.4 million deaths worldwide every year. ${ }^{1,2,3}$ So, Hypertension is one of the leading cause of death as a "silent killer" because its symptoms can go undetected until damage to end organ has occurred. Because of this, it is one of the most significantly under-diagnosed and under-treated medical conditions all over the world.

Several classes of antihypertensive agents have been in clinical use, including diuretics, $\alpha$-blockers, $\beta$-blockers, angiotensin converting enzyme (ACE) inhibitors, angiotensin II type 1 receptor blockers (ARB), and organic calcium channel blockers (CCBs), that can be used as monotherapy or in combination. ${ }^{4}$ A patient has to consume these drugs for lifelong accommodating and adjusting to all their side effects. Because hypertension is mostly a noncurable disease. Among them, CCBs exert most

$1 *$ Dr. Md. Mahmudur Rahman Siddiqui, Associate Professor, Department of Medicine, Anwer Khan Modern Medical College \& Hospital. e-mail: dr.mahmud99@yahoo.com ${ }^{2}$ Dr. Sumaiya Sultana Binte Mosharraf, Registrar, Department of Ophthalmology, Shahabuddin Medical College \& Hospital, Dhaka

${ }^{3}$ Dr. Rubayet Sheikh Giasuddin. Assistant Professor, Department of Medicine, Anwer Khan Modern Medical College \& Hospital, Dhaka

${ }^{4}$ Dr. Nadia Islam, Associate Professor, Department of Pharmacology Therapeutics, Anwer Khan Modern Medical College, Dhaka

${ }^{5}$ Dr. Sohail Mirza, Assistant Professor, Department of Dermatology, Shaheed Taj Uddin Ahmed Medical College, Gazipur

*Corresponding Author

Date of submission: 15.10 .2018 Date of acceptance: 28.11 .2018

AKMMC J 2019; 10(1) : 77-83 
potent antihypertensive action and are widely used as a first lineantihypertensive drug in elderly with very few contraindication. ${ }^{5-9}$ These reliable CCBs not only use in hypertension but also in angina and peripheral vascular disease. ${ }^{10-11}$ The aim of the review is to assess the potential advantages and disadvantages of newer CCBs with a focus of its benefits in varied cardio vascular diseases.

\section{Calcium Channel Blocker (CCB)}

Calcium channel blockers (CCBs), comprising two subclasses-dihydropyridines and nondihydropyridines. Calcium channel blockers (CCBs) share a common mechanism of action. However, the manner in which they exert their pharmacological effects is different between subclasses. Dihydropyridine (DHP) CCBs tend to be more potent vasodilators than non-dihydropyridine (nonDHP) agents, whereas the latter have more marked negative inotropic effects. Both subclasses have a similar capacity to lower BP; however, non-DHPs appear to offer potential advantages in the management of patients with chronic kidney disease and diabetic nephropathy. Since its invention in 1960s, Dihydropyridines have undergone several changes to optimize their efficacy and safety for the management of cardiovascular disease. ${ }^{4,12,13,14}$

Four generations of dihydropyridines are now available. The first-generation nicardipine and nifedipine are potent and low cost antihypertensive drug. However, because of their short duration and rapid onset of vasodilator action, these drugs were more likely to be associated with adverse effects like; headache, blood pressure fluctuation. The new second generation slow-release and short-acting preparations like benidipine, and efonidipine allowed better control of blood pressure and a reduction in some adverse effects. The thirdgeneration dihydropyridines, amlodipine and azelnidipine exhibit more stable pharmacokinetics, are less cardio-selective and, consequently, well tolerated in patients with heart failure. The fourthgeneration highly lipophilic dihydropyridines, lercanidipine, cilnidipine and lacidipine are now available which provide a real degree of therapeutic comfort in terms of stable activity, a reduction in adverse effects and a broad therapeutic spectrum, especially in myocardial ischemia and potentially in congestive heart failure. ${ }^{12,15}$

\section{CCBs- Mechanism of Action}

The voltage-gated calcium channel consists of 4 subunits, $\alpha 1, \alpha 2-\delta, \beta$ and $\gamma$. An $\alpha 1$ subunit is the dominant component of the calcium channels and constitutes pore structure for ion conduction. Ten different $\alpha 1$ subunits have been reported and each of them has specific distribution and ion conductance of its channels. These distinct subunits characterize the channel properties of L-, N-, T-, P-, Q- and Rtype calcium channels. Of these channels, L-type calcium channels are the main targets of the CCB. ${ }^{16,17}$

Traditionally, CCBs exert dilator action on vascular smooth muscle cells by inhibiting calcium entry through L-type calcium channels. Recently, novel types of CCBs have been developed that blocking activity on $\mathrm{N}$ - (cilnidipine) and/or $\mathrm{T}$ - (mibefradil and efonidipine) type calcium channels as well as Ltype channels, and these properties produce additional benefits associated with reductions in cardiovascular events and renal injury. For example, the blockade of N-type or T-type calcium channels in cardiac pacemaker cells may suppress heart rates, which could therefore reduce cardiac events and improve survival. ${ }^{18,19}$

Cilnidipine is a recently developed $\mathrm{CCB}$, and possesses both L- and N-type calcium channel blocking activity. ${ }^{20}$ Since N-type calcium is distributed along the nerve and in the brain, cilnidipine is anticipated to exert specific action on nerve activity, such as inhibition of the sympathetic neuro transmitter release. N-type calcium channels regulate sympathetic nerve activity, and aberrant sympathetic nerve stimulation is a major cause of hypertension. ${ }^{18,21}$ Because sympathetic nerve stimulation causes release of norepinephrine which causes vasoconstriction, increase cardiac contraction, increase heart rate, decrease of renal blood flow, renin secretion. All these actions increases systemic blood pressure (Fig-1).15 Cilnidipine inhibits $\mathrm{N}$-type $\mathrm{Ca} 2 \mathrm{p}$ channels more potently than other $\mathrm{Ca} 2 \mathrm{p}$ channel blockers and 
several in vitro studies conducted by Nap A et al. (2004), have demonstrated that cilnidipine attenuates norepinephrine release from sympathetic nerve endings. ${ }^{22,23}$ Furthermore, such effects have been observed in in vivo experiments using anesthetized rats $^{24}$ and dogs. ${ }^{25}$ This article reviews the current understanding of the pharmacological profile and clinical utility of cilnidipine as a unique antihypertensive drug.

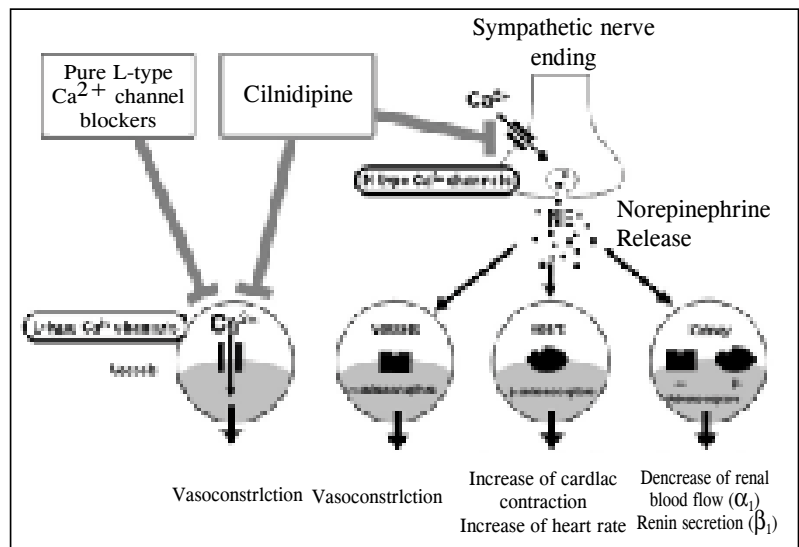

Fig. 1. Deagrammatic representation of $\mathrm{L} / \mathrm{N}$ dual action of cilnidipine

Ref: KS Chandra, et al. The fourth-generation Calcium channel blocker: Cilnidipine. Indian Heart Journal 2013; 165: 691-695.

\section{Role of $4^{\text {th }}$ Generation CCBs in Various Clinical Settings}

Antihypertensive Effects

The antihypertensive effect of cilnidipine has been demonstrated in various studies conducted among hypertensive patients. Once-daily administration of cilnidipine $(5-20 \mathrm{mg}$ ) for 1-3 weeks decreased the 24-hour average BP significantly from $149 \pm 4 / 88 \pm 2 \mathrm{mmHg}$ to $141 \pm 3 / 82 \pm 2 \mathrm{mmHg}$ without any change in the pulse rate. Cilnidipine is thus a useful antihypertensive drug that may not cause an excessive decrease in blood pressure or a reflex tachycardia. ${ }^{26}$ Sympatholytic profiles of cilnidipine observed in both in vitro and in vivo, are also observed in clinical practice. ${ }^{24}$ In clinical studies, conducted by Nagahama S et al. (2007) and Iimura O et al (1993) the antihypertensive effect of cilnidipine has been demonstrated in hypertensive patients, ${ }^{27}$ and also in patients with severe hypertension. ${ }^{28}$ In a study conducted in 2920 hypertensive patients, treatment with cilnidipine and angiotensin receptor blocker showed significant reductions in heart rate, particularly in those with a higher baseline heart rate, whereas there were few adverse reactions associated with central nervous functions. ${ }^{27}$

In another study conducted by Minami $\mathrm{J}$ et al. (2000) in patients with mild to moderate essential hypertension, Cilnidipine significantly decreased the $24 \mathrm{~h}$ blood pressure by $6.5 \pm 1.7 \mathrm{~mm} \mathrm{Hg}$ systolic $(\mathrm{P}<0.01)$ and $5.0 \pm 1.1 \mathrm{mmHg}$ diastolic $(\mathrm{P}<0.01)$, also cilnidipine did not significantly change the heart rate. ${ }^{29}$ It was concluded by Minami $\mathrm{J}$ et al., that Cilnidipine is effective as a once daily antihypertensive agent and causes little influence on heart rate. ${ }^{29}$ Hoshide et al (2005)30 demonstrated that the reductions in heart rate were significantly greater in the cilnidipine group than the amlodipine group in a 24-h ambulatory blood pressure monitoring study with hypertensive patients. ${ }^{30}$ Kai T et al. (2009) conducted a study to examine the effects of cilnidipine, on blood pressure, pulse rate, and autonomic functions in patients with mild-tomoderate hypertension. The systolic or diastolic blood pressure decreased significantly from $151 \pm 15$ $\mathrm{mmHg}$ to $129 \pm 14 \mathrm{mmHg}$ or $84 \pm 11 \mathrm{mmHg}$ to $71 \pm 9 \mathrm{mmHg}$, respectively. No significant changes in pulse rate was reported. ${ }^{31}$

Cilnidipine significantly decreased morning hypertension. In ACHIEVE-ONE trial, the effects of cilnidipine on morning hypertension were examined in 2319 patients treated with cilnidipine for 12 weeks. Cilnidipine reduced both morning systolic blood pressure (SBP) and pulse rate (PR) more markedly in patients with higher baseline morning SBP and PR. Also a 12-week treatment with cilnidipine significantly, restored abnormal nocturnal dipping in hypertensive patients. ${ }^{32,33,34}$ Cilnidipine has been clinically demonstrated to be effective for morning hypertension and white-coat hypertension, which is closely associated with sympathetic nerve over activation. ${ }^{35}$ Cilnidipine, also a good option for combination therapy. Treatment with cilnidipine and ARB showed a significant reduction in SBP $(\mathrm{p}<0.0001)$ and DBP $(\mathrm{p}<0.0001) .27$ 


\section{Other Effect on Heart}

Six months treatment with cilnidipine improved LV diastolic function in patients with hypertensive heart disease by suppressing cardiac sympathetic over activity. ${ }^{36}$ The CANDLE trialand other clinical studies have demonstrated that treatment with cilnidipine 5-10 mg/day for 8 weeks can improve left-ventricular systolic function independently of blood pressure changes. ${ }^{37}$ Cilnidipine causes a greater decrease in Left Ventricular Mass (LVM) in essential hypertension than quinapril. ${ }^{38}$

The cardioprotective action of cilnidipine has been analyzed in a rabbit model of myocardial infarction, in which cilnidipine decreased the myocardial interstitial norepinephrine levels during ischemia and reperfusion periods, leading to reduction of the myocardial infarct size and incidence of ventricular premature beats. ${ }^{39}$ Furthermore, in vivo experimental data have suggested that cilnidipine shows antianginal effects in the experimental model of vasopressin-induced angina and improvement of the ventricular repolarization abnormality in the canine model of long QT syndrome. ${ }^{40,41}$

\section{Effect on Kidney}

Hypertension is one of the most important risk factors for the progression of renal disease. Moreover, chronic renal dysfunction, proteinuria or albuminuria are independent risk factors for cerebrovascular and cardiovascular diseases. The CARTER clinical studies have shown that cilnidipine, has better renal protection compared with other dihydropyridine CCBs. ${ }^{42}$ CARTER study which is a multi-center, open-labeled, and randomized trial compared the antiproteinuric effect of cilnidipine with that of amlodipine in 339 hypertensive patients with kidney disease. This study suggests that cilnidipine is superior to amlodipine in preventing the progression of proteinuria in hypertensive patients when coupled with a renin-angiotensin system inhibitor. ${ }^{42}$

Podocytes act as a permeability barrier in glomeruli restricting the passage of large molecules like albumin. Albuminuria is the primary indicator of a defective glomerular filtration barrier. Various glomerular diseases that induce proteinuria also shown structural damage to podocytes. ${ }^{43}$ A decrease in the number of podocytes has been reported in diabetic nephropathy. ${ }^{44}$ Cilnidipine provides protection of glomeruli by both afferent and efferent arteriolar vasodilation in glomeruli (Figure 2). This causes reduction of glomerular pressure further result in significant reduction of proteinuria. ${ }^{43}$

In an open-label, randomized controlled trial the effects of cilnidipine in 60 patients with CKD were investigated. After 12 months, proteinuria and heart rate were significantly decreased in the cilnidipine treated patients, but proteinuria increased and heart rate remained unchanged in patients treated with CCB acting on L-type channel (L-CCB). ${ }^{45}$ TACTICAL trial evaluatedantioxidative and antiproteinuriceffects of cilnidipine as comparedto amlodipine. This study reported significant decrease in the urinary albumin/creatinine ratio after 6 month treatment with cilnidipine as compared to amlodipine treatment $(\mathrm{p}<0.005) .{ }^{46}$ In clinical studies, Rose and Ikebukoro ${ }^{47}$ demonstrated that cilnidipine significantly decreased urinary albumin excretion without affecting serum creatinine concentration in hypertensive patients, which is comparable to the angiotensin converting enzyme inhibitor benazepril. ${ }^{47}$ Recently, prevalence of cardiovascular disease and cardiovascular mortality have been suggested to be closely associated with renal function; namely, cardioerenal connection. ${ }^{46}$ Thus, the renal protective effects of cilnidipine may secondarily contribute to cardioprotection. ${ }^{48}$

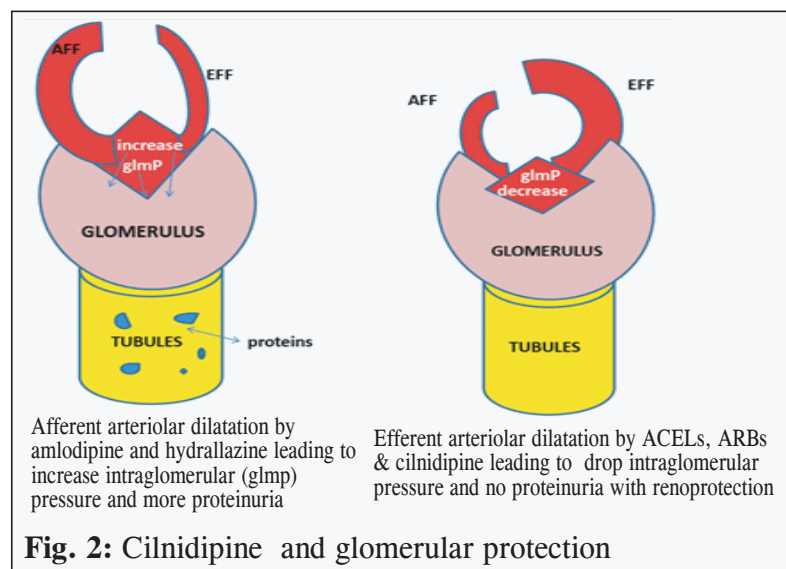

Ref: Shete MM. Cilnidipine: Next Generation Calcium Channel Blocker. Journal of the Association of Physicians of India April 2016; 64: 95-99. 
What is New in New Generation Calcium Channel Blocker Effect on Insulin Sensitivity

Cilnidipine improve insulin sensitivity, possibly due to its vasodilatory action without stimulating sympathetic nervous activity. The benefit effects of cilnidipine on glucose metabolism is an important site for the treatment of hypertensive patients with insulin resistance and/or diabetes mellitus. ${ }^{49}$ Hypertensive obese patients treated with $10 \mathrm{mg}$ of cilnidipine showed improved in insulin resistance. ${ }^{50}$

\section{Effect on CCBs induced ankle edema}

Ranjan Shetty, et al. (2013) have conducted a study in patients of essential hypertension with amlodipine induced ankle edema. They had found that cilnidipine resulted in complete resolution of amlodipine induced edema in all the cases without significant worsening of hypertension or tachycardia. Cilnidipine is an acceptable alternative antihypertensive for patients with amlodipine-induced edema. ${ }^{51}$

\section{Drawback of Cilnidipine}

Cilnidipine is contraindicated in patients with severe aortic stenosis, cardiogenic shock, recent history of unstable angina or MI, heart failure and hypotension. The recommended adult oral dosage of Cilnidipine is $5-10 \mathrm{mg}$ once daily. The dosage can be increased up to $20 \mathrm{mg}$, if needed. But in our clinical observation, $5 \mathrm{mg}$ of Cilnidipine in comparison to 5mg of Amlodipine is very weak as a single antihypertensive drug. Sometimes it is require to start with $10 \mathrm{mg}$ of Cilnidipine for adequate antihypertensive effect. But we did not get enough clinical study evidence regarding this issue.

\section{Conclusion}

Hypertension is one of the most common noncommunicable disease seen in primary care sating and a major public health problem. It is one of the most significantly under-diagnosed and under-treated medical conditions all over the world. If left untreated can led to various complications. For more than 50 years, $\mathrm{CCB}$ is one of the most reliable antihypertensive drug. Several classes of CCBs are in clinical use for the treatment of hypertension because of potent vasodepressor action. Among CCB, Cilnidipine is a promising 4th generation $\mathrm{Ca}^{2+}$ channel blocker with its unique action onsympathetic
N-type $\mathrm{Ca}^{2+}$ channels inhabit norepinephrine release and leads to vasodilatation, decrease in heart rate and increase in renal blood flow. Cilnidipine causing less reflex tachycardia, less pedal edema, better control of proteinuria, suppressing podocyte damage, increasing insulin sensitivity. Therefore, Cilnidipine as CCB can be a good choice in hypertensive patients with diabetes, chronic kidney disease and in patients developing pedal edema with other CCB.

\section{Conflict of interest: none}

\section{Referances}

1. Tiwaskar M, Langote A, Kashyap R et al. Journal of The Association of Physicians of India March 2018; 66: 59-64.

2. Causes of death 2008: data sources and methods. Available from: http://www.who. int/healthinfo/ global_burden_disease/ cod_2008.

3. Lim SS, Vos T, Flaxman AD, et al. A comparative risk assessment of burden of disease and injury attributable to 67 risk factors and risk factor clusters in 21 regions, 1990-2010: a systematic analysis for the Global Burden of Disease Study 2010. Lancet 2012; 380: 2224-60.

4. Ozawa Y, Hayashi K, Kobori H. New Generation Calcium Channel Blockers in Hypertensive Treatment. Curr Hypertens Rev. 2006 May 1; 2(2): 103-111. doi:10.2174/157340206776877370.

5. Chobanian AV, Bakris GL, Black HR, et al. The seventh report of the joint national committee on prevention, detection, evaluation, and treatment of high blood pressure: The JNC 7 report. JAMA 2003; 289: 2560-2572. [PubMed: 12748199]

6. Gong L, Zhang W, Zhu Y, et al. Shanghai trial of nifedipine in the elderly (STONE). J Hypertens 1996; 14: 1237-1245. [PubMed: 8906524]

7. Staessen JA, Fagard R, Thijs L, et al. Randomised double-blind comparison of placebo and active treatment for older patients with isolated systolic hypertension. The systolic hypertension in Europe (Syst-Eur) trial investigators. Lancet 1997; 350: 757-764. [PubMed: 9297994]

8. Liu L, Wang JG, Gong L, et al. Comparison of active treatment and placebo in older chinese patients with isolated systolic hypertension. Systolic hypertension in China (Syst-China) 
collaborative group. J Hypertens 1998; 16: 1823-1829. [Pub Med: 9869017]

9. National intervention cooperative study in elderly hypertensives study group. Randomized doubleblind comparison of a calcium antagonist and a diuretic in elderly hypertensives. Hypertension 1999; 34: 1129-1133. [Pub Med: 10567194]

10. Triggle DJ. Calcium channel antagonists: clinical uses-past, present and future. Biochem Pharmacol 2007; 74: 1-9.

11. Taylor SH. Usefulness of amlodipine for angina pectoris. Am J Cardiol1994; 73: 28A-33A.

12. Aoum K, Berdeaux A. Dihydropyridines from the first to fourth generation: better effects and safety. Therapie. 2003 Jule Aug; 58: 333e339.

13. Weir MR. Calcium channel blockers: differences between subclasses. Am J Cardiovasc Drugs. 2007; 7: 5e15.

14. Frishman WH. Calcium channel blockers: differences between subclasses. Am J Cardiovasc Drugs. 2007; 7: 17e23.

15. Chandra KS, Ramesh G. The fourth-generation Calcium channel blocker: Cilnidipine. Indian Heart Journal 2013; 165: 691-695.

16. Ertel EA, Campbell KP, Harpold MM, et al. Nomenclature of voltage gated calcium channels. Neuron. 2000; 25: 533 e535 [Pub Med 10774722].

17. Miljanich GP, Ramchandran J. Antagonists of neuronal calcium channels: structure, function \& therapeutic implications. Annu Rev Pharmacol Toxicol. 1995; 35: 707e734 [Pub Med 7598513].

18. Takahara A, Sugiyama A, Satoh Y, et al. Cardiovascular effects of an L/N-type $\mathrm{Ca} 2+$ channel blocker cilnidipine assessed in the chronic atrioventricular conduction block dogs. J Pharmacol Sci 2004; 96: 219-223. [Pub Med: 15492462].

19. Harada K, Nomura M, Nishikado A, et al. Clinical efficacy of efonidipine hydrochloride, a $\mathrm{T}$ type calcium channel inhibitor, on sympathetic activities. Circ J 2003; 67: 139-145. [Pub Med: 12547996]

20. Fujii S, Kameyama K, Hosono M, et al. Effect of cilnidipine, a novel dihydropyridine $\mathrm{Ca}++-$ channel antagonist, on $\mathrm{N}$-type $\mathrm{Ca}++$ channel in rat dorsal root ganglion neurons. J Pharmacol Exp Ther 1997; 280: 1184-1191. [Pub Med, 9067302]

21. Iyer RP, Lindsey ML, Chilton RJ. A Two-forOne Bargain: Using Cilnidipine to Treat Hypertension and Its Comorbidities. The Journal of Clinical Hypertension 2013; 15: 455-457.

22. Nap A, Mathy MJ, Balt JC, et al. The evaluation of $\mathrm{N}$ type channel blocking properties of cilnidipine and other voltage dependent calcium antagonists. Fundam Clin Pharmacol. 2004; 18: 309e319.

23. Hosono M, Fujii S, Hiruma $\mathrm{T}$, et al. Inhibitory effect of cilnidipine on vascular sympathetic neurotransmission \& subsequent vasoconstriction in spontaneously hypertensive rats. Jpn J Pharmacol. 1995; 69: 127e134.

24. Takahara A, Koganei $\mathrm{H}$, Takeda $\mathrm{T}$, et al. Antisympathetic \& hemodynamic property of a dual L/N type calcium channel blocker cilnidipine in rats. Eur J Pharmacol. 2002; 434: 43e47.

25. Nagayama T, Yoshida M, Suzukikusaba M, et al. Effect of cilnidipine, a novel dihydropyridine calcium channel blocker, on adrenal catecholamine secretion in anesthetized dogs. J Cardiovasc Pharmacol. 1998; 32: 479e484.

26. Tominaga $\mathrm{M}$, Ohya $\mathrm{Y}$, Tsukashima $\mathrm{A}$, et al. Ambulatory blood pressure monitoring in patients with essential hypertension treated with a new calcium antagonist, cilnidipine. Cardiovascular Drugs Therapeutics 1997; 11: 43-8.

27. Nagahama $\mathrm{S}$, Norimatsu $\mathrm{T}$, Maki $\mathrm{T}$, et al. The effect of combination therapy with $\mathrm{L} / \mathrm{N}$ type calcium channel blocker cilnidipine, \& an angiotensin II receptor blocker on blood pressure \& heart rate in Japanese hypertensive patients: an observational study conducted in Japan. Hypertens Res. 2007; 30: 815e822.

28. Iimura O, Ishi M, Inagaki Y, et al. Study of FRC-8653 (cilnidipine) in patients with severe hypertension. Jpn Pharmacol Ther. 1993; 21: S155eS170.

29. Minami J, Kawano Y, Makin Y et al. Effects of cilnidipine, a novel dihydropyridine calcium antagonist, on autonomic function, ambulatory blood pressure and heart rate in patients with essential hypertension. Br J Clin Pharmacol 2000; 50: 615-20. 
30. Hoshide S, Kario K, Ishikawa J, et al. Comparison of the effects of cilnidipine and amlodipine on ambulatory blood pressure. Hypertens Res. 2005; 28: $1003 \mathrm{e} 1008$.

31. Kai T, Kuzumto Y. Effects of a dual L/N-type calcium channel blocker cilnidipine on blood pressure, pulse rate, and autonomic functions in patients with mild to moderate hypertension. Clin Exp Hypertens 2009; 31: 595-604.

32. Ashizawa N, Seto S, Shibata Y, et al. Bedtime administration of cilnidipine controls morning hypertension. Int Heart J 2007; 48: 597-603.

33. Kario K, Nariyama J, Kid $\mathrm{H}$ et al. Effect of a novel calcium channel blocker on abnormal nocturnal blood pressure in hypertensive patients. J Clin Hypertens (Greenwich) 2013; 15: 465-72.

34. Shete MM. Cilnidipine: Next Generation Calcium Channel Blocker. Journal of the Association of Physicians of India April 2016; 64: 95-99.

35. Yamagishi T. Beneficial effect of cilnidipine on morning hypertension \& white coat effect in patients with essential hypertension. Hypertens Res. 2006; 29: 339e344.

36. Kosaka $\mathrm{T}$, Nakagawa $\mathrm{M}$, Ishida $\mathrm{M}$, et al. Cardioprotective effect of an L/N-type calcium channel blocker in patients with hypertensive heart disease. J Cardiol 2009; 54: 262-72.

37. Ma ZY, Li L, Zhong XZ, Tan HW, et al. Cilnidipine improves left-ventricular midwall function independently of blood pressure changes in Chinese patients with hypertension. J Cardiovasc Pharmacol 2007; 49: 33-8.

38. Sakata $\mathrm{K}$, Yoshida $\mathrm{H}$, Tamekiyo $\mathrm{H}$, et al. Comparative effect of Cilnidipine and quinapril on left ventricular mass in mild essential hypertension. Drugs Exp Clin Res 2003; 29: 117-23.

39. Nagai $\mathrm{H}$, Minatoguchi $\mathrm{S}$, Chen $\mathrm{XH}$, et al. Cilnidipine, an NpL type dihydropyridine calcium channel blocker, suppress the occurrence of ischemia/reperfusion arrhythmia in rabbit model of myocardial infarction. Hypertens Res. 2005; 28: $361 \mathrm{e} 368$

40. Takahara A, Sugiyama A, Hashimoto K. Long term blockade of $\mathrm{N}$ type calcium channels reversed the ventricular electrical remodelling in the canine model of long QT syndrome. Circ J. 2006; 70: 575.
41. Saitoh M, Sugiyam A, Nakamura Y, et al. Antianginal effects of $\mathrm{L}$ type $\mathrm{N}$ type calcium channel blocker cilnidipine assessed using vasopressin induced experimental angina model in rats. J Pharmacol Sci. 2003; 91: 152 P (abstract).

42. Fujita $\mathrm{T}$, Ando K, Nishimura $\mathrm{H}$, et al. Cilnidipine versus Amlodipine Randomised Trial for Evaluation in Renal Desease (CARTER) Study Investigators. Antiproteinuric effect of the calcium channel blocker cilnidipine added to reninangiotensin inhibition in hypertensive patients with chronic renal disease. Kidney Int 2007; 72: 1543-9.

43. Arif E, Nihalani D. Podocytes as a therapeutic target. Ann Clin Exp Hypertension 2013; 1: 1004.

44. Giunti S, Barit D, Cooper ME. Mechanisms of diabetic nephropathy: Role of hypertension. Hypertension 2006; 48: 519-526.

45. Hatta T, Takeda K, Shiotsu Y et al. Switching to an L/N-type calcium channel blocker shows renoprotective Effects in patients with chronic kidney disease: the Kyoto Cilnidipine Study. J Int Med Res 2012; 40: 1417-28.

46. Soeki $\mathrm{T}$, Kitani $\mathrm{M}$, Kusunose $\mathrm{K}$ et al. Renoprotective and antioxidant effects of cilnidipine in hypertensive patients. Hypertens Res 2012; 35: 1058-62.

47. Rose GW, Ikebukoro H. Cilnidipine as effective as benazepril for control of blood pressure and proteinuria in hypertensive patients with benign nephrosclerosis. Hypertens Res. 2001; 24: $377 \mathrm{e} 383$.

48. Go AS, Chertow GM, Fan D, et al. Chronic kidney disease and risks of death, cardiovascular events and hospitalization. N Engl J Med. 2004; 351: 1296e1305.

49. Yagi S, Goto S, Yamamoto $\mathrm{T}$, et al. Effect of cilnidipine on insulin sensitivity in patients with essential hypertension. Hypertens Res 2003; 26: 383-7.

50. Ueshiba H, Miyachi Y. Effects of the long-acting calcium channel blockers, amlodipine, manidipine and cilnidipine on steroid hormones and insulin resistance in hypertensive obese patients. Intern Med 2004; 43: 561-5.

51. Shetty Ranjan, Vivek G, et al. Excellent tolerance to cilnidipine in hypertensives with amlodipine induced edema. N Am J Med Sci. 2013 Jan; 5: $47 \mathrm{e} 50$ 